\title{
Наталия Васильева
}

Российская академия наук, Москва

\section{Традиционное и новое в русской топонимической терминологии}

\section{1. Предварительные замечания}

Топонимика как раздел ономастики - вполне традиционная наука, обладающая устойчивым терминологическим аппаратом и методами исследования. Достаточно определен и сам объект исследования - географические названия. В отличие, например, от сферы эргонимии/хрематонимии, где новые объекты влекут за собой и необходимость в новых терминах, ср. [Gałkowski 2010: 613-614; Siwiec 2011], для объектов топонимических исследований resp. топонимической номинации бурный количественный рост не является характерным. Тем не менее, новые термины появляются и в топонимике, и это не может не отражаться на общем облике терминосистемы.

Целью настоящей статьи является попытка показать такие терминологические новации, которые связаны с новыми исследовательскими позициями и которые зависят не только от положения дел в топонимике как разделе ономастики, но и от парадигм «апеллятивной» лингвистики. Но прежде чем говорить о новом, следует определить, что такое «традиционное» для русской топонимической терминологии XXI в. Думаю, что любой российский ономатолог скажет, что это словник «Словаря русской ономастической терминологии» Н. В. Подольской (первое издание вышло в 1978 г., второе издание - в 1988 г.). Второе издание словаря фиксирует состояние терминологии конца 80. гг. XX в., однако это же состояние характерно и для 90. гг. и даже позже. Например, в диссертации В. С. Картавенко, посвященной становлению региональной топонимической системы и защищенной в 2012 г, специально указывается, что в работе используется сложившаяся система ономастической терминологии, отраженная в словаре Н. В. Подольской, и лишь в ряде случаев автор уточняет определения отдельных терминов [Картавенко 2012: 14].

В качестве текстовых источников, т.е. сферы непосредственного функционирования терминов, в статье использованы, прежде всего, материалы 
журнала «Вопросы ономастики» (официальный сайт журнала www. onomastics.ru/, c 2004 г. вышло 15 номеров), а также материалы ономастических конференций, проходивших в России в последние годы. Это конференции Ономастика Поволэсья [ОП-2010; ОП-2012], конференции Этнолингвистика. Ономастика. Этимология в Екатеринбурге [ЭОЭ-2009; ЭОЭ-2012]. Много статей по топонимике содержат материалы конференций по региональной ономастике, проводимых в г. Майкопе (Адыгея, Россия) [ПОРО2010; ПОРО-2012]. Также были использованы отдельные статьи и монографии по топонимике 2000-2012 гг.

\section{2. Понятие базового термина}

Для представления терминологии как системы важно выделить базовый термин и дать ему характеристику. Для топонимической терминологии это, безусловно, термин топоним. Этот термин является базовым как в «старом» терминоведческом смысле, т.е. как термин, который исторически был положен в основу терминологии, ср. [Гринев-Гриневич 2008: 61], так и с точки зрения теории категоризации, идущей от когнитивной психологии и развиваемой современной когнитивной лингвистикой. В настоящее время, вслед за Э. Рош, разработавшей теорию, которую впоследствии назвали теорией прототипов, принято различать три основных уровня категоризации [Rosch 1973; Лакофф 2004: 28 сл.]. Это базовый, вышестоящий (суперординатный) и нижестоящий (субординатный) уровни. Базовый уровень считается исходным и ведущим. Так, в таксономии «собака» - «животное» - «пудель» собака находится на базовом уровне, на вышестоящем уровне находится животное, на нижестоящем - пудель. Эксперименты показали, что испытуемые при выборе названия для какой-либо вещи из целого ряда возможных имен выбирают то, которое относится к категории именно базового уровня [Лакофф 2004: 72].

Перечисленные уровни категоризации свойственны, на наш взгляд, и иерархии терминов в терминологических системах. Так, в рассматриваемой топонимической системе термин топоним репрезентирует категорию базового уровня. На суперординатном уровне выступает абионим (общий термин для имени собственного неживого объекта), а на субординатном уровне появляются различные спецификации, ср. ойконим, астионим, урбаноним и др. При таком представлении терминологической системы сразу становится ясно, что новации затрагивают именно субординатный уровень. Поэтому рассмотрение терминологических систем сквозь призму данной категоризации, объединенное с элементами тезаурусного подхода, позволит, на наш взгляд, сделать шаг вперед на пути координации терминологии, особенно в межъязыковом аспекте [Vasil'eva 2011: 43]. 


\section{3. Способы терминообразования на основе базового термина}

Возвращаясь к теме традиционного и нового в терминологии топонимики, отметим, что термин топоним был и неизменно остается базовым. Рассмотрим способы терминообразования на его основе.

1. Деривация. Этим способом образован адъектив топонимный. Теперь уже можно с уверенностью сказать, что, несмотря на усилия ономатологов в конце 80. гг. прошлого века, в том числе и автора словаря Н. В. Подольской, внедрить это прилагательное в русскую ономастическую терминологию как производное от термина топоним (в отличие от прилагательного топонимический как производного от термина топонимика), эксперимент не удался. Прилагательное топонимический употребляется и как производное от топонимика, и как производное от топоним, ср. топонимическое пространство, топонимическое словообразование, топонимический процесс (предлагалось: топонимное пространство, топонимное словообразование, топонимный проиесс, ср. [Подольская 1988: 136]). По-видимому, синкретизм производящего термина (например, топонимический процесс можно представить связанным как с топонимом, так и с топонимикой как совокупностью топонимов), а также все-таки некоторая искусственность для русского языка формы топонимный не позволили этому прилагательному занять свое четкое место в системе. Однако в некоторых российских ономастических школах, например, петрозаводской, дистрибуция прилагательных топонимический vs. moпонимный соблюдается четко, ср. [Кузьмин 2003].

2. Приращение терминоэлемента (аналог детерминативных композитов). В данном случае термин топоним получает модификатор слева. Если этот модификатор (терминоэлемент) является первым компонентом ономастического термина на -оним, то интерпретация модели является однозначной: $\mathrm{N}+$ топоним 'топоним, образованный от N'. Например, антропотопоним - это топоним, образованный от антропонима. Данная модель является продуктивной и позволяет создавать в рамках ономастики однозначно интерпретируемые термины, ср. агиотопоним. В. С. Картавенко приводит в своей диссертации примеры того, какие термины предлагались учеными при квалификации населенных пунктов типа Рождественское, Покровка, Троицкое: «А. М. Селищев использовал термин иерковные имена, А. В. Суперанская называет подобные населенные пункты церковными наименованиями, Г. В. Агапова дает следующее пространное название: официально-иерковная группа терминов, связанных с названием иерковного прихода, два термина - названия церковного характера и названия по цеерквам использует Б. Н. Перлин, М. В. Горбаневский оперирует терминами агиотопоним, агиоойконим» [Картавенко 2012: 13]. В. С. Картавенко соглашается с М. В. Горбаневским, что последние два термина удачны, так как они соответствуют 
критериям, предъявляемым к терминам (однословные, интернациональные, построены по определенной модели, а также способны к деривации) [ibidem], что совершенно справедливо.

Термин топоним может и сам стоять в левой позиции в производном термине. Однако в этом случае наблюдается эллипсис элемента -оним, ср. топооснова $={ }^{*}$ топонимооснова, топоформант $={ }^{*}$ топонимоформант, тополексем $a=$ "топонимолексема. Подобная компрессия присуща и рассмотренным выше терминам, ср. антропотопоним = "антропонимотопоним. Понятно, что такая избыточность выражения должна быть преодолена, отсюда и привычные всем термины, уже не осознаваемые как эллиптизированные.

3. Термин-словосочетание с базовым термином как вершиной. Переход от базового терминологического уровня на нижестоящий посредством такой модели является очень распространенным в топонимической терминологии. Так, в обоих изданиях словаря Н. В. Подольской таких терминов более двух десятков, ср. вторичный, двойной, субстратный топоним и пр. Научные тексты последних лет принесли не так много новых примеров данной модели, ср. игровой топоним, прецедентный топоним. Однако если мы на эти два термина посмотрим внимательно, то увидим, что они специфицируют не термин топоним, а являются спецификаторами (видами) сложных терминов игровой оним и прещедентное имя.

\section{4. Термины-наименования топонимических объектов}

Обратимся к терминам, именующим топонимические объекты. Это, как известно, основной массив терминов ономастики (и топонимики в том числе). Споры о том или ином термине оказываются зачастую спорами не о содержании понятия (интенсионале), а об объеме понятия (экстенсионале). Приведем пример из другой сферы ономастики. Например, включать ли в понятие эргоним названия фирм? Определение термина (и интенсионал понятия) эргоним как 'собственного имени делового объединения людей' [Подольская 1988: 151] не препятствуют этому. Значит, речь идет лишь об экстенсионале данного понятия, и дискуссия об этом даже не является собственно лингвистической.

Однако среди топонимических терминов есть один, который не поддается простому толкованию. Это термин микротопоним, давший вместе со своим коррелятом (макротопоним) название этой конференции. Приведем полностью определение термина микротопоним из словаря Н. В. Подольской.

«МИКРОТОПОНИМ - Собственное имя (чаще) природного физико-географического объекта, (реже) созданного человеком, имеющее узкую сферу употребления; функционирующее в пределах лишь микротерритории, 
известное узкому кругу людей, живущих вблизи именуемого микрообъекта, в т. ч. микрогидроним, микроойконим, микроороним, микрохороним, названия урочищ, хозяйственных угодий, микросооружений (колодцев, мостов, будок, вышек, зимовий, кордонов, охотничьих домиков и т.п.)» [ibidem: 83].

Далее в данной словарной статье следует важное примечание: «М(икротопоним) - результат естественного процесса номинации: м(икротопоним) часто находится на грани употребления слова нарицательного и собственного, однако он не является "микрословом". Многие из м(икротопонимов) очень древни; м(икротопонимы) объединяются в микротопонимические системы, функционирующие в пределах одного населенного пункта» [ibidem].

В этом определении, которое, к сожалению, нечасто цитируется полностью, очень важной является формулировка «микротопоним не является “микрословом"», т.е. семантика терминоэлемента «микро» не имеет отношения ни к объекту, ни к значимости его наименования. Здесь я полностью солидарна с мнением профессора Р. Шрамка, высказанным в докладе на конференции. «Микро» в данном случае относится к сфере функционирования названия, т.е. коммуникативной сфере, которая является узкой и - что важнее - полностью входит в пределы личной сферы обитателей данной местности (о понятии личной сферы говорящего применительно к ономастике см. [Васильева 2009: 172-183]). Можно предположить, что частые дискуссии среди ономатологов, возникающие в связи с микротопонимами, связаны как раз с тем, что у объектов, которые обозначаются термином микротопоним, два типа наблюдателя: один - это языковая личность из локального сообщества, крепко держащая сам объект и обозначающее его слово в своей личной сфере; другой - это языковая личность топонимиста-исследователя, записывающего в полевых, как правило, условиях и сами названия, и связанные с ними топонимические легенды, и вторгающегося тем самым в чужую личную сферу. Примеры дискурсивных характеристик микротопонимов приводятся в работе Л. А. Климковой, исследовавшей нижегородскую микротопонимию. Она различает микротопонимическую коннотативность внутри самой микротопонимической системы, т.е. «для своих», и вне ее - для представителя иносистемы [Климкова 2008: 84]. Еще одно замечание связано с поиском авторства термина микротопоним. Это трудно решаемая проблема. По-видимому, мы можем говорить либо о коллективном авторстве, либо о своеобразном законе создания термина на базе интернациональных терминоэлементов. Эти элементы - греческие и латинские корни и аффиксы (радиксоиды и аффиксоиды) - представляют собой резервуар, из которого любой может черпать нужные корни и морфемы. А поскольку за время функционирования научных терминологий на европейских языках сложились готовые стереотипные корреляции (ср. гипер-/2ипо-, эндо-/экзо-, микро-/макро- и пр.), то пара терминов микротопоним и макротопоним могла возникнуть одновременно в нескольких местах. 
Выше мы упоминали, что для топонимических объектов характерна константность: объекты «река», «озеро», «город» и «деревня» существовали на карте с давних пор и существуют по сей день. Однако новая российская действительность оказалась способной вызвать к жизни новые топонимические объекты - клубные и коттеджные поселки. Для этих объектов пока нет своего термина (комоним все-таки больше подходит для названия исторически сложившегося села, чем для недавно построенной группы престижных загородных домов в виде замков). Так что данная группа онимов представляет интерес не как материал для топонимической терминологии (системного термина еще нет), а как непосредственный номинативный материал, базирующийся на довольно причудливых принципах номинации. В работах Т. П. Соколовой можно найти примеры названий коттеджных поселков, возникших за последние 10 лет на территории Подмосковья. Это иностранные и псевдоиностранные слова, так называемые перенесенные топонимы, контаминации разных по происхождению слов, а также примеры «креативной деривации». Cр.: ZORINO-SPORT-VILLAGE, Андрейково Light, Cалтыковка-Prestige, Дубна Ривер Клаб, Когоvіпо, Бельгийская деревня, Карповы (sic!) Bapы, Гельвеция, Гагаринлэнд и пр. [Соколова 2012]. Российские ономатологи рассматривают подобные названия в рамках экологии языка и наблюдают в последний год определенный спад подобной «креативности».

\section{5. Термины, относящиеся к способам описания объектов}

В настоящее время в России получило развитие этнолингвистическое изучение собственных имен. Это направление связано с именами Н. И. Толстого, С. М. Толстой, Е. Л. Березович, М. Э. Рут и др. Прежде всего нужно отметить, что сам термин этнолингвистический употреблялся до Н. И. Толстого в ином значении. Так, например, этнолингвистическое исследование подразумевало выявление и интерпретацию этнотопонимов, т.е. топонимов, образованных от этнонимов [Березович 1999]. Сначала этнолингвистическое направление смыкалось с тем направлением, которое называют лингвострановедческим и которое уделяло особое внимание фоновой семантике имени. Согласно одному из определений, фоново-коннотативная семантика имени представляет собой «совокупность социально-значимых ассоциаций, обусловленных национальной культурой и представляющих собой сумму прошлых речевых и контекстных определений в пределах языкового коллектива» [Аникина 1988: 7]. Лингвокультурный подход, таким образом, как бы выхватывает, по образному выражению Е. Л. Березович, из всего ономастического континуума отдельные «меченые атомы», в то время как этнолингвистический подход в духе Н. И. Толстого базируется на ином принципе - на изучении всего континуума и на вопросах кодирования в топонимии информации о духовной культуре народа [Березович 1999: 137]. 
В связи с методикой извлечения этнокультурной информации появляются два термина для представления ономастической семантики: семантическая вертикаль и семантическая горизонталь [Березович 2007: 60 сл.]. Семантическая вертикаль создается иерархией семантических пластов - от поверхностных до глубинных. Наиболее явный и доступный для этнолингвистического изучения уровень вертикальной семантики - уровень мотивационного значения имени: Тещина тропа - тропинка, по которой парни бегали к теще на блины. Культурная семантика может залегать глубже - на коннотативном уровне. Так, название аптеки Медея (г. Белгород) может вызвать у всех, кто знаком с античной культурой, нежелательные коннотации, в то время как придумавший это название человек всего лишь взял «медицинский корень» МЕД. Семантическая горизонталь - это способность имени вступать в деривационные процессы и семантическое «рассеивание» имени, а также продвижение имени в другие семантические коды и прецедентность имени. Сp. Париж - как прозвище красивого парня [ibidem].

Развитие в топонимике получила и теория семантического поля с разделением на зоны значения (концептуальное ядро, прагматическая зона, семантические связи) [ibidem: 58]. Не обошлось без топонимического концепта [Щербак 2009] и концептуальности; под последней понимается «совокупный объем представлений о возможностях его (имени. - Н. В.) применения - языковые и экстралингвистические знания, связанные с использованием ономастического знака, сложившиеся у носителей данного языка» [Голомидова 1998: 16]. Внесла свой вклад в топонимическую терминологию и теория прецедентности (прецедентный топоним, ср. Москва, Рим, Ватерлоо).

Далее я приведу списком (без упоминания авторов) ряд неудачных, на наш взгляд, терминов. Это топоэффектор - фактор, способствующий активации топонима в газетном тексте (например, какое-либо событие в данном населенном пункте); неясный термин топоморфный код, а также выражение топонимная идеограмма, претендующее занять место выражения номинативныій признак.

\section{6. «Зная место в системе, знаешь термин; зная термин, знаешь место в системе»}

Завершая наблюдения над русскими топонимическими терминами, продемонстрируем, как функционирует этот сформулированный в 30. гг. XX в. профессором Николаем Владимировичем Юшмановым [Юшманов 1937: 703] и поддержанный впоследствии профессором Александром Александровичем Реформатским терминологический принцип. Обратимся к видам ойконимов. В первом издании словаря Н. В. Подольской находим термин полисоним и его определение: «Вид ойконима. Собственное имя любого 
города» [Подольская 1978: 112], а также примечание: термин заменен на астионим. Во втором издании словаря полисоним уже отсутствует, есть только астионим. Комоним как собственное имя любого сельского поселения присутствует в обоих изданиях. Таким образом, сначала мы наблюдаем, как действует принцип выравнивания - уходит синоним (практически никогда не употреблявшийся термин полисоним) и получается скорректированное соотношение:

Полисоним = астионим vs. комоним (избыточная структура) $\rightarrow$ астионим vs. комоним (оптимальная структура).

С помощью терминологического принципа Юшманова - Реформатского определяется лакуна в терминологической системе и по возможности заполняется. Так, для обозначения названий внутригородских объектов уже достаточно долго существует термин урбаноним. Для названий аналогичных объектов в селе системного термина долго не было. Но он появился, можно сказать, как результат решения пропорции, ср.:

город: урбаноним = село: $\mathrm{X}$

Термин виконим (от лат. vicus 'деревня') был предложен Беатой Афельтович [Афельтович 2007: 118] и к настоящему времени прочно занял свое место в системе. Свидетельством его укорененности стали видовые наименования, выделенные Р. Разумовым, ср.: виконимы-характеристики (Школьная улица), виконимыл-посвящения (улица Гоголя, улица Красных партизан), эвсемантические виконимы (Цветочная улица, Светлая улица) [Разумов 2012a: 132-133].

\section{7. Заключение}

Существуют две возможности обновления терминологических систем: вводить новые термины для новых объектов или переосмысливать старые понятия, оставляя им их традиционные обозначения. В русской топонимической терминосистеме гармонично уживаются обе этих возможности. Есть новации на уровне терминов - наименований объектов (виконим), есть пока пустая клетка в топонимической терминологической таблице, предназначенная для короткого термина для названия нового объекта российской действительности - престижного коттеджного поселка. Базовый термин топонимической терминосистемы топоним остался прежним, равно как и термин микротопоним, однако количество знания об этих объектах существенно увеличилось, также изменился угол зрения. Соответственно, появились другие сопряженные с этими терминами термины и понятия, бытующие в «апеллятивной» лингвистике (конщепт, языковая картина мира, личная сфера говорящего, прецедентный феномен и др.). При анализе топоними- 
ческой терминосистемы не следует, таким образом, оставлять без внимания понятийный аппарат и, соответственно, термины, которые относятся к способам описания и представления объектов, поскольку именно они несут в себе теоретический инновационный заряд.

\section{Библиография}

Аникина Марина, 1988, Лингвострановедческий анализ русских антропонимов: личное имя, отчество, фамилия, Автореф. дис. ... канд. филол. Наук, Москва.

Афельтович Беата, 2007, Общепольская ономастическая конференция «Новые имена собственные. Новый взгляд», «Вопросы ономастики» 4, 114-121.

Березович Елена, 1999, Этнолингвистическая проблематика в работах по ономастике (1987-1998), «Известия Уральского гос. ун-та. Гуманитарные науки» 13, вып. 2, 128-141.

Березович Елена, 2007, Язык и традиционная культура: Этнолингвистические исследования, Москва.

Березович Елена, 2009, Русская топонимия в этнолингвистическом аспекте. Пространство и человек, Москва.

Березович Елена, 2010, Русская топонимия в этнолингвистическом аспекте. Мифопоэтический образ пространства, Москва.

Васильева Наталия, 2009, Собственное имя в мире текста, Москва.

Васильева Светлана, 2005, Топонимическое поле «Человек», «Политическая лингвистика» 16 , 123-131.

Голомидова Марина, 1998, Искусственная номинация в ономастике, Екатеринбург.

Гринев-Гриневич Сергей, 2008, Терминоведение, Москва.

Картавенко Вера, 2009, О развитии ономастической терминологии, «Филологические науки» 2, 72-80.

Картавенко Вера, 2012, Становление региональной топонимической системы (Западный регион России), Автореф. дисс. ... доктора филол. наук, Смоленск.

Климкова Людмила, 2008, Нижегородская микротопонимия: коннотативный аспект, «Вестник Челябинского университета» 6, 80-85.

Кондакова Ирина, 2006, Динамика топонимического образа, [in:] Актуальные проблемы лингвистики ХХІ века, Киров, 112-116.

Кузьмин Денис, 2003, Ареальная дистрибуция топонимных моделей Беломорской Карелии, Дисс. ... канд. филол. наук, Петрозаводск.

Лакофф Джордж, 2004, Женщины, огонь и опасные вещи: Что категории языка говорят нам о мылилении / Пер. с англ. И. Б.Шатуновского, Москва.

Литовкина Анна, 2010, Исследование семантики онимов с позищий когнитивной лингвистики, «Вестник Иркутского государственного лингвистического университета» 3, 33-39.

ОП-2010, Ономастика Поволжья. Материаль ХІІ Международной научной конференции, Казань.

ОП-2012, Ономастика Поволжья. Материаль ХІІІ Международной конферениии, Ярославль.

Подольская Наталия, 1978, Словарь русской ономастической терминологии, Москва.

Подольская Наталия, 1988, Словарь русской ономастической терминологии. 2-е изд., переработанное и дополненное, Москва.

ПОРО-2009, Проблемь общей и региональной ономастики: Материалы VII международной научной конференции, Майкоп. 
ПОРО-2012, Проблемы общей и региональной ономастики: Материалы VIII международной научной конференции, Майкоп.

Разумов Роман, 2012, К вопросу об упорядочении терминологии в области эргонимии, [in:] ОП-2012, 46-51.

Разумов Роман, 2012a, Современная виконимия Рязанской области, [in:] Этнолингвистика. Этимология. Ономастика, ч. 1., Екатеринбург, 131-133.

Соколова Татьяна, 2012, Иностранные топонимы в Подмосковье, [in:] ОП-2012, 262-266.

Щербак Антонина, 2009, Основные типы ономастических кониептов (на материале региональной концептосферы), «Вестник Тамбовского гос. университета», вып. 10 (78), 169175.

ЭОЭ-2009, Этнолингвистика. Ономастика. Этимология. Материалы Международной научной конференции, Екатеринбург.

ЭОЭ-2012, Этнолингвистика. Ономастика. Этимология. Материаль Международной научной конференции, т. 1-2, Екатеринбург.

Юшманов Николай, 1937, Грамматика иностранных слов, [in:] Словарь иностранных слов, Москва, 689-723.

Gałkowski Artur, 2010, Problemi di terminologia onomastica. Contributi per un dibatto, «RIOn» XVI (2010), 2, 604-624.

Rosch Eleanor, 1973, Natural Categories, [in:] Cognitive Psychology, vol. 4, 328-350.

Siwiec Adam, 2011, Fachtermini in der onomastischen Theorie und ihre Rolle bei der Klassifikation und Analyse der Namen von Handelsobjekten, «Namenkundliche Informationen» 99/100, Leipzig, 15-30.

Vasil'eva Natalija, 2011, Die Terminologie der Onomastik, ihre Koordinierung und lexikographische Darstellung, «Namenkundliche Informationen», 99/100, Leipzig, 31-45.

\section{Natalija Vasileva}

\section{Innovative and traditional aspects of Russian toponymic terminology}

\section{(Summary)}

The article discusses the state of Russian toponymic system over the past two decades. The Russian Dictionary of Onomastic Terminology by Natalija V. Podolskaja (1988) is taken as a point of reference, the terms of which are relevant to this day. The article characterizes two options of renewal for terminology systems: introduction of new terms for new objects or rethinking old concepts and leaving the old traditional terms. The article concludes that both of these options harmoniously coexist in the Russian toponymic terminology system. It is also noted that the analysis of toponymic terminology system should focus on the terms that relate to methods for the description and presentation of objects, since they bear theoretical innovation charge.

Słowa kluczowe: toponimy, rosyjska termonologia toponimiczna.

Key words: toponyms, Russian toponymic terminology. 